\title{
BMJ Open Non-invasive prenatal diagnosis using fetal DNA in maternal plasma: a preliminary study for identification of paternally-inherited alleles using single nucleotide polymorphisms
}

\author{
J J Chen, ${ }^{1}$ J A M A Tan, ${ }^{1}$ K H Chua, ${ }^{1}$ P C Tan, ${ }^{2}$ E George ${ }^{3}$
}

To cite: Chen JJ, Tan JAMA, Chua KH, et al. Non-invasive prenatal diagnosis using fetal DNA in maternal plasma: a preliminary study for identification of paternallyinherited alleles using single nucleotide polymorphisms. BMJ Open 2015;5:e007648. doi:10.1136/bmjopen-2015007648

- Prepublication history and additional material is available. To view please visit the journal (http://dx.doi.org/ 10.1136/bmjopen-2015007648).

Received 28 January 2015 Revised 19 May 2015 Accepted 16 June 2015

CrossMark

\footnotetext{
${ }^{1}$ Department of Biomedical Science, Faculty of Medicine, University of Malaya, Kuala Lumpur, Malaysia

${ }^{2}$ Department of Obstetrics and Gynaecology, Faculty of Medicine, University of Malaya, Kuala Lumpur, Malaysia

${ }^{3}$ Assunta Hospital, Petaling Jaya, Selangor, Malaysia
}

Correspondence to Professor J A M A Tan; maryanne@um.edu.my

\section{ABSTRACT}

Objectives: Single nucleotide polymorphism (SNP) with a mutation can be used to identify the presence of the paternally-inherited wild-type or mutant allele as result of the inheritance of either allele in the fetus and allows the prediction of the fetal genotype. This study aims to identify paternal SNPs located at the flanking regions upstream or downstream from the $\beta$-globin gene mutations at CD41/42 (HBB:C.127_130delCTTT), IVS1-5 (HBB:C.92+5G>C) and IVS2-654 (HBB:c.316197C>T) using free-circulating fetal DNA.

Setting: Haematology Lab, Department of Biomedical Science, University of Malaya.

Participants: Eight couples characterised as $\beta$-thalassaemia carriers where both partners posed the same $\beta$-globin gene mutations at CD41/42, IVS1-5 and IVS2-654, were recruited in this study.

Outcome measures: Genotyping was performed by allele specific-PCR and the locations of SNPs were identified after sequencing alignment.

Results: Genotype analysis revealed that at least one paternal SNP was present for each of the couples. Amplification on free-circulating DNA revealed that the paternal mutant allele of SNP was present in three fcDNA. Thus, the fetuses may be $\beta$-thalassaemia carriers or $\beta$-thalassaemia major. Paternal wild-type alleles of SNP were present in the remaining five fcDNA samples, thus indicating that the fetal genotypes would not be homozygous mutants.

Conclusions: This preliminary research demonstrates that paternal allele of SNP can be used as a noninvasive prenatal diagnosis approach for at-risk couples to determine the $\beta$-thalassaemia status of the fetus.

\section{INTRODUCTION}

Thalassaemia is the most common autosomal recessive disorder. It has been identified as a global health problem and approximately $3-10 \%$ of the world's population are thalassaemia carriers. ${ }^{1}$ In Malaysia, $4.5 \%$ of the population are $\beta$-thalassaemia carriers, and

\section{Strengths and limitations of this study}

- The preliminary study shows that SNP(s) with either paternally-inherited wild-type or mutant allele can be used for the detection of the inheritance of either paternal allele in fcDNA extracted from maternal plasma.

- This SNP-based analysis permits non-invasive prenatal diagnosis in couple at risk of carrying the same mutation.

- However, a $\beta$-thalassaemia major diagnosis in a foetus can be excluded only by detecting a paternally-inherited wild-type allele.

this disorder is present mainly in the Malays and Chinese. ${ }^{2}$ Couples who are both thalassaemia carriers possess a $25 \%$ risk of producing a child with $\beta$-thalassaemia major, a disorder that requires lifelong blood transfusions and expensive iron-chelation therapy to remove excess iron from the body. Affected children suffer a chronic illness and complications of $\beta$-thalassaemia major poses a heavy load on a country's transfusion and paediatric services. The only "cure" is a successful bone marrow transplantation or gene therapy with supportive management.

Genetic counselling and prenatal diagnosis play important roles for successful prevention programmes. Prenatal diagnosis can be performed using chorionic villi (CV) sampling or amniocentesis to determine the genotype of the fetus. Both techniques produce accurate results and investigators are developing methods for non-invasive prenatal diagnosis (NIPD).

Current approaches for NIPD have focused mainly on the isolation and examination of fetal DNA. Fetal DNA is present in $3-10 \%$ of the total DNA extracted from maternal plasma of pregnant women and the 
concentration increases with gestational age. ${ }^{3-5}$ Fetal DNA was first reported in the detection of the SRY and RhD genes. ${ }^{4-7}$ Recent studies have reported the use of fetal DNA for the detection of paternally-inherited mutations, which differ from the maternally-inherited mutations. $^{8-10}$

The genotype of a fetus can be predicted by screening for the presence of the paternally-inherited mutation when a couple has different mutations in the same gene. Women who are heterozygous for a specific mutation carry one wild-type and one mutant allele. In the presence of a paternally-inherited mutant allele, the fetus is at risk of inheriting two mutant genes. In the absence of a paternally-inherited mutant allele, the fetus inherits one or both wild-type alleles, thus excluding the risk of inheriting two mutant genes.

Early studies in the detection of paternally-inherited mutations were successfully carried out on achondroplasmia, myotonic dystrophy and Huntington's disease. ${ }^{11}$ In $\beta$-thalassaemia, the presence of the paternally-inherited mutation in the free-circulating DNA (fcDNA) can indicate that the fetus will be either a $\beta$-thalassaemia carrier or a $\beta$-thalassaemia major carrier. fcDNA contains the free-circulating fetal DNA (fcFDNA) and free-circulating maternal DNA (fcMDNA). The absence of the paternally-inherited mutation shows that the fetus will not be a $\beta$-thalassaemia major. By using allele-specific primers and specific TaqMan probes, Chiu et aी showed that homozygosity for the $\beta$-globin gene mutation at CD41/42 was excluded when the paternally-inherited mutation was absent in the fcDNA. In addition, Li et $a l^{10}$ also showed the feasibility of amplification using peptide-nucleic-acid, which demonstrates high binding affinity to specific sequences for detection of paternally-inherited mutations in $\beta$-thalassaemia. This approach, however, is ineffective when a couple has the same mutation - the paternally and maternally-inherited mutant allele are the same.

In situations where a couple has the same mutation, analysis of single nucleotide polymorphism (SNP) can be used to trace the inheritance of mutations as the SNP can be with either of the alleles. The presence of a SNP with the paternal mutant allele or the absence of a SNP with the paternal wild-type allele indicates the inheritance of the paternal mutant allele in the fetus. To the contrary, the presence of a SNP with the paternal wild-type allele or the absence of a SNP with the paternal mutant allele will indicate that the fetus will inherit either one or both wild-type alleles, thus producing a normal or carrier fetal genotype, respectively. For example, Ding et $a l^{12}$ used a SNP marker to detect the presence of a paternally inherited mutant allele in the $\beta$-globin gene and reported that the fetus is not at risk for thalassaemia major when the SNP with the paternally-inherited mutant allele was absent.

A simple molecular approach based on allele-specific PCR (AS-PCR) in combination with sequence analysis for haplotype determination on individual samples was reported in previous studies. ${ }^{13-15}$ Hence, this study aims to identify SNP located in the flanking regions upstream, adjacent or downstream from the $\beta$-globin gene mutations at CD41/42 (HBB:c.127_130delCTTT), IVS1-5 (HBB:c.92+5G>C) and IVS2-654 (HBB: c.316-197C $>$ T). The results from this study will demonstrate the usefulness of SNP for identification of paternally-inherited alleles in NIPD.

\section{METHODOLOGY}

\section{Sample collection}

Maternal plasma, and parental and CV DNA used in this study were archived clinical samples sent for prenatal diagnosis of $\beta$-thalassemia from 2008 to 2011. Ethical approval was obtained from the Medical Ethics Committee of University Malaya Medical Centre (MEC Ref No: 896.8) in accordance with the Declaration of Helsinki. Informed and written consent was obtained from patients before blood collection and CV sampling. DNA from eight couples who had been previously characterised as $\beta$-thalassaemia carriers with $\beta$-globin gene mutations at CD41/42 (couples 1, 2 and 3), IVS1-5 (couples 4, 5 and 6) and IVS2-654 (couples 7 and 8), were used in this study. Maternal plasma was isolated from maternal blood samples by centrifugation at $1900 \times \mathrm{g}$ for $10 \mathrm{~min}$ at $4^{\circ} \mathrm{C}$. The plasma was transferred into $1.5 \mathrm{~mL}$ microcentrifuge tubes without aspirating the buffy coat layer and recentrifuged at $16000 \times \mathrm{g}$ for $10 \mathrm{~min}$ at $4^{\circ} \mathrm{C}$ to remove the cellular nucleic acids. The plasma was aspirated and stored in $1 \mathrm{~mL}$ aliquots at $-20^{\circ} \mathrm{C}$.

\section{DNA extraction}

The fcDNA was extracted using a QIAamp Circulating Nucleic Acid kit (Qiagen) with a QIAvac 24 Plus vacuum manifold (Qiagen, Germany) according to the manufacturer's instructions. Briefly, frozen samples were thawed at room temperature. Lysis buffer and proteinase $\mathrm{K}$ were added and the lysates were then transferred into QIAamp Mini columns connected to a vacuum manifold. The fcDNA was absorbed onto the silica membrane as the lysate was drawn through the column by vacuum pressure ( -800 to -900 millibar). The bound nucleic acids were washed, eluted with $50 \mu \mathrm{L}$ elution buffer and stored at $-20^{\circ} \mathrm{C}$.

\section{Fetal DNA enrichment}

To eliminate the risk of contamination, fetal enrichment was carried out following a modified method. ${ }^{10}{ }^{16} \mathrm{Gel}$ tank, gel comb and excision blade were cleaned with DNA-away spray and sterilised by exposing to UV for $30 \mathrm{~min}$. Molecular grade agarose gel and Tris-Borate EDTA buffer used in the gel tank were freshly prepared. Only one sample was processed at a time to avoid cross contamination. A total of $25 \mu \mathrm{L}$ of the extracted fcDNA were electrophoresed in a $1.5 \%(\mathrm{w} / \mathrm{v})$ agarose gel at 90 volt for $30 \mathrm{~min}$. DNA fragments of $100-300 \mathrm{bp}$ were excised with a sterile scalpel blade. The resulting DNA 
was extracted and purified using the QIAquick Gel Extraction kit (Qiagen, Germany) and the eluted DNA was stored at $-20^{\circ} \mathrm{C}$.

\section{Genotyping of parental DNA}

Three common mutations in the $\beta$-globin gene (CD41/ 42, IVS1-5 and IVS2-654) were studied. Two separate AS-PCR assays were carried out for each mutation: one amplified only the normal allele, while the other amplified only the mutant allele. The amplification reagents for the $50 \mu \mathrm{L}$ PCR reactions consisted of 1X HotstarTaq Plus PCR buffer, $0.8 \mathrm{mM}$ deoxyribonucleotide triphosphates, $0.5 \mu \mathrm{M}$ forward and reverse primers (see online supplementary table S1), 0.1 unit HotStarTaq Plus (Qiagen, Germany), $500 \mathrm{ng}$ parental and their respective CV DNA. The amplification was carried out with a denaturation and enzyme activation step at $95^{\circ} \mathrm{C}$ for 5 min, followed by 40 cycles of denaturation at $94^{\circ} \mathrm{C}$ for $1 \mathrm{~min}$, an appropriate annealing temperature (see online supplementary table S1) for $45 \mathrm{~s}$, extension at $72^{\circ} \mathrm{C}$ for 90 or $120 \mathrm{~s}$ with a final extension at $72^{\circ} \mathrm{C}$ for $10 \mathrm{~min}$. Sequencing was carried out with the same pair of amplification primers using the BigDye Terminator V.3.1 Cycle Sequencing Kit (Applied Biosystems).

\section{Identification of SNPs in the paternal alleles in fcDNA}

The sequences of the wild-type and mutant alleles of each parental DNA were aligned and compared using ClustalX 2.0 (European Bioinformatics Institute) and Sequence Scanner V1.0 (Applied Biosystems). SNPs that were present in either paternal wild-type or mutant alleles were identified. Two sets of primers were designed specifically to amplify six SNPs located in two different sequences (see online supplementary table S2). As illustrated in figure $1 \mathrm{~A}$, the first set of primers $\beta 1 \mathrm{~F}$ and $\beta 1 \mathrm{R}$ amplified a sequence containing five SNPs ( $r$ s 35755129, rs 10768684, rs 74234654, rs 200771769 and rs 10742584), while the second set of primers $\beta 2 \mathrm{~F}$ and $\beta 2 \mathrm{R}$ amplified a sequence containing one SNP (rs 7946748). DNA amplification and sequencing were carried out as stated previously in genotyping of parental DNA.

\section{RESULTS}

Genotyping of the eight parental DNA identified six paternal SNPs (figure 1A). The number and location of the paternal SNPs are shown in figure 1B. The presence of paternally-inherited SNP was detected by visualisation of double peaks in the chromatograms (figure 2). For example, genotyping of DNA sample for couple 1 showed that the SNP with the paternal mutant allele (1PM) was present at two locations: rs 74234654 (adenine) and rs 10742584 (adenine). The paternal wild-type allele (1PWt) and both maternal wild-type (1MWt) and mutant alleles (1MM) showed the presence of thymine at location rs 74234654 and guanine at location rs 10742584 (top and middle panels in figure 2). Sequencing of fcDNA (sample 1) with primers $\beta 1 \mathrm{~F}$ and $\beta$ 1R showed double peaks at location rs 10742584 (adenine/guanine) and rs 74234654 (adenine/ thymine). This observation confirmed the presence of the paternally-inherited mutant allele in the fcDNA. Thus, the fetus would have the paternally-inherited mutant allele and would be either a $\beta$-thalassaemia carrier or a $\beta$-thalassaemia major carrier with the $\beta$-globin gene mutation at CD41/42. Our results concur with the prenatal diagnosis result of the respective $\mathrm{CV}$ sample where the fetus was confirmed as a $\beta$-thalassaemia major homozygous for the $\beta$-globin gene mutation in CD41/42.

Table 1 shows the summary of results for the inheritance of paternal alleles and the prediction of fetal genotypes. Of the eight samples analysed, the paternally-inherited mutant alleles were observed in three fcDNA samples (samples 1, 3 and 8). The genotype of the fetuses would be either heterozygous or homozygous for $\beta$-globin gene mutations at CD41/42 for fcDNA samples 1 and 3, and IVS2-654 for fcDNA sample 8. The other five fcDNA samples (samples 2, 4, 5, 6 and 7) possessed the paternally-inherited wild-type allele. Thus, the genotype of these fetuses would be either a wild-type or heterozygous for the $\beta$-globin gene mutation at CD41/42. Comparison of these results with prenatal diagnosis results carried out using CV DNA showed concordance. CV sampling was carried out before the non-invasive testing while genotyping of the parents was carried out prior to prenatal diagnosis.

\section{DISCUSSION}

NIPD using fcDNA extracted from maternal plasma allows the determination of the genotype of the fetus without undergoing invasive procedures such as amniocentesis and CVS. Detection of paternally-inherited mutation in the fcDNA is a straightforward and costeffective method to predict the genotype of the fetus. However, most previous studies focused on the detection of paternally-inherited mutant alleles that were different from the mutation present in the mother. ${ }^{10} 1718$ The genotype of the fetus is either homozygous wild-type or heterozygous for the particular allele of interest when paternally-inherited mutation is absent.

Studies utilising SNPs to detect submicroscopic chromosomal abnormalities, mainly on trisomy 13, 18 and 21, have been reported. ${ }^{19} 20$ For single gene disorder, Ding $e t a l^{12}$ used a single SNP (rs 2187610), which is a $\mathrm{C} / \mathrm{G}$ polymorphism, to detect the presence of the $\mathrm{G}$ allele in the mother with a CC genotype. The presence or absence of the $\mathrm{G}$ allele (linked to either the wild-type or mutant allele) allows the prediction of the fetal genotype. The use of SNP at one location, however, shows insufficient sensitivity for detection of paternal alleles as only 16 of 50 samples were found to have CG genotype.

This preliminary study aims to determine multiple potential SNPs present in the $\beta$-globin gene. $^{21}$ Genotyping of parental DNA in this study was carried 
A

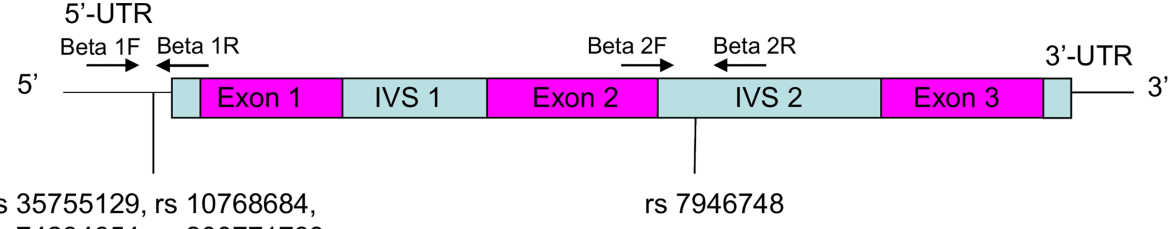

rs 35755129, rs 10768684 ,

rs 74234654 , rs 200771769 ,

rs 10742584

Location

B

\begin{tabular}{|c|c|c|c|c|c|c|}
\hline \multirow{2}{*}{ Couple } & \multicolumn{6}{|c|}{ Location of paternal SNP } \\
\cline { 2 - 7 } & rs & rs & rs & rs & rs & rs \\
& 35755129 & 10768684 & 74234654 & 200771769 & 10742584 & 7946748 \\
\hline 1 & & & A/T & & A/G & \\
\hline 2 & T/A & & & & & \\
\hline 3 & A/T & & A/T & & A/G & \\
\hline 4 & & & & & & C/A \\
\hline 5 & & G/A & & & & \\
\hline 6 & T/A & & & & & \\
\hline 7 & & & & A/G & & \\
\hline 8 & T/A & & T/A & & & \\
\hline
\end{tabular}

Figure 1 (A) Location of six paternal SNPs in the $\beta$-globin gene. (B) Location and number of paternal SNPs that present the respective mutation for each couple. Five SNPs (rs 35755129, rs 10768684, rs 74234654, rs 200771769 and rs 10742584) are amplified using $\beta 1 \mathrm{~F}$ and $\beta 1 \mathrm{R}$, while SNP at rs 7946748 is amplified using $\beta 2 \mathrm{~F}$ and $\beta 2 \mathrm{R}$. Genotype G/A (mutant/wild-type) refers to guanine or adenine on paternal mutant allele or wild-type allele, respectively. A-adenine, T-thymine, C-cytosine, G-guanine; SNP, single nucleotide polymorphism.

out using AS-PCR. To achieve higher discrimination and specificity of the in-house developed AS-PCR primers, a mismatch was created three or four bases upstream from the $3^{\prime}$ end of the primers. AS-PCR was used for genotyping as it is cost-effective and can be carried out in a general screening and diagnostic laboratory equipped with a gradient thermal cycler.

Mutations at CD41/42, IVS1-5 and IVS2-654 of the $\beta$-globin gene were selected as they are common mutations in the Malay and Chinese ethnic groups in Malaysia. For the couples who were heterozygous for the $\beta$-globin gene mutation at CD41/42 and IVS2654, genotyping with AS-PCR was carried out to detect SNPs located at the upstream region of their respective mutations in the $\beta$-globin gene. The sequences were aligned and paternal SNPs were detected from all five couples (couples 1, 2, 3, 7 and 8).

For the couples who were heterozygous for the $\beta$-globin gene mutation at IVS1-5, AS-PCR was carried out to detect SNPs located at the upstream region of the mutation. One paternal SNP (rs 35755129) was present in couple 6, one paternal SNP (rs 10768684) was observed in couple 5 and no paternal SNP was observed in couple 4. AS-PCR was repeated on the wild-type and mutant allele for couple 4 using another two sets of primers (SNP 3NF and SNP 4R; SNP 3DR and SNP 4R) to detect paternal SNP located at the downstream region of the IVS1-5 mutation. Sequence alignment showed the presence of one paternal SNP (rs 7946748).

\section{Determination of the inheritance of the paternal allele}

Amplification and sequencing of fcDNA with primers $\beta \quad 1 F$ and $\beta \quad 1 \mathrm{R}$ allowed the identification of paternally-inherited wild-type or mutant alleles in the maternal plasma. In couple 1, paternal SNPs were present at locations rs 10742584 (adenine) and rs 74234654 (adenine) of the $\beta$-globin gene, resulting in a double peak (adenine/thymine and adenine/guanine) at both locations. This result indicates that the mutant allele was present in the fetus. Therefore, the fetal genotype can be either a $\beta$-thalassaemia carrier or major for the $\beta$-globin gene mutation at CD41/42.

One advantage of this study is that it allows fetal genotype prediction to be carried out for couples in whom both partners are carrying identical mutation. However, if the paternally-inherited mutant allele is present or the paternally-inherited wild-type allele is absent in the fcDNA, the result will still be inconclusive. Nonetheless, the result shows that five of eight couples (more than half) are not at risk of having a homozygous mutant fetus and the screening is more efficient compared to the study carried out by Ding et al. ${ }^{12}$ This preliminary study will be continued with a larger number of couples to further validate the efficiency. 
Figure 2 Identification of SNP in the paternal alleles. Top panel refers to the alignment of the haplotype sequence of the couple. The following middle panels (1PM, 1PWt, 1MM, 1MWt) refer to the sequence of the wild-type and mutant allele of couple 1. The bottom panel refers to the sequence of enriched fcDNA from maternal plasma. Double peaks were observed at two locations (rs 10742584 and rs 74234654), indicating the presence of paternal mutant allele. PM, paternal mutant allele; PWt, paternal wild-type allele; $\mathrm{MM}$, maternal mutant allele; $\mathrm{MWt}$, maternal wild-type allele; SNP, single nucleotide polymorphism.

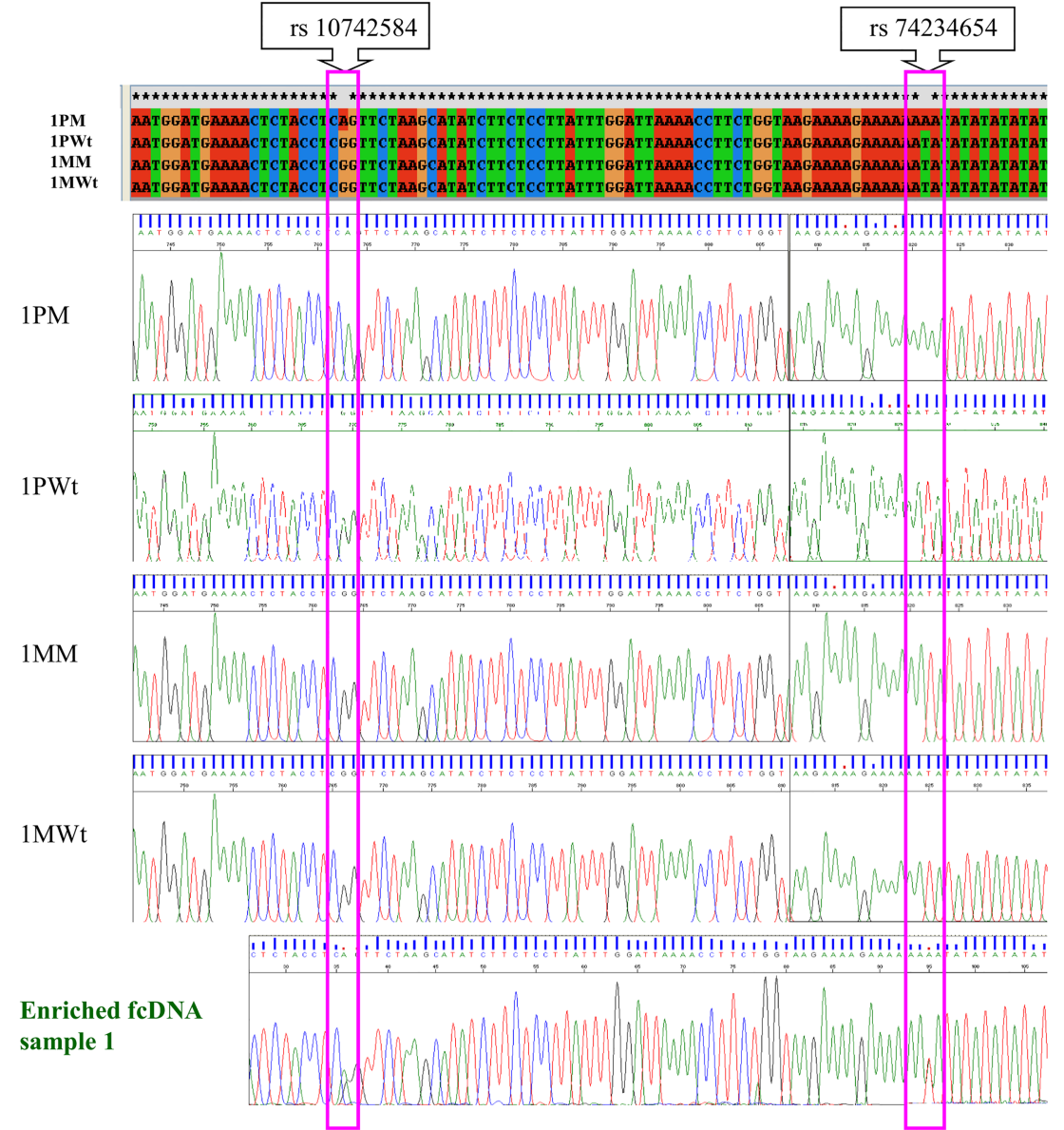

\section{Importance of fetal enrichment}

This study also demonstrated the importance of the fetal DNA enrichment steps prior to amplification and sequencing of the fcDNA. The fetal DNA enrichment steps were carried out with some modification, described earlier. Initially, the extracted fcDNA was used for direct PCR amplification (primers $\beta 1 \mathrm{~F}$ and $\beta 1 \mathrm{R}$ ) without undergoing fetal DNA enrichment. Sequencing results revealed the absence of paternally-inherited SNPs at locations rs 10742584 and rs 74234654 in the fcDNA that did not undergo fetal DNA enrichment (figure 3). However, the fcDNA that did undergo fetal DNA enrichment showed double peaks at the mentioned SNP locations. The absence of paternally-inherited SNPs could be due

Table 1 Inheritance of paternal allele and prediction of fetal genotype. Paternal mutant allele was present in samples 1,3 and 8.

\begin{tabular}{|c|c|c|c|c|}
\hline No & $\begin{array}{l}\text { Parental } \\
\text { genotype }\end{array}$ & $\begin{array}{l}\text { Presence of } \\
\text { paternally-inherited } \\
\text { mutant allele }\end{array}$ & $\begin{array}{l}\text { Fetal genotype } \\
\text { prediction }\end{array}$ & CV genotype \\
\hline 1 & $\beta / C D 41 / 42$ & Yes & Carrier or major & $\begin{array}{l}\text { CD41/42/CD41/42 } \\
\text { (major) }\end{array}$ \\
\hline 2 & $\beta / C D 41 / 42$ & No & Normal or carrier & $\beta / C D 41 / 42$ (carrier) \\
\hline 3 & $\beta / C D 41 / 42$ & Yes & Carrier or major & $\begin{array}{l}\text { CD41/42/CD41/42 } \\
\text { (major) }\end{array}$ \\
\hline 4 & $\beta /$ IVS1-5 & No & Normal or carrier & $\beta /$ IVS1-5 (carrier) \\
\hline 5 & $\beta /$ IVS1-5 & No & Normal or carrier & $\beta /$ IVS1-5 (carrier) \\
\hline 6 & $\beta /$ IVS1-5 & No & Normal or carrier & $\beta / \beta$ (normal) \\
\hline 7 & $\beta /$ IVS2-654 & No & Normal or carrier & $\beta / \beta$ (normal) \\
\hline 8 & $\beta /$ IVS2-654 & Yes & Carrier or major & $\beta /$ IVS2-654 (carrier) \\
\hline
\end{tabular}


Beta $1 \mathrm{~F}+$ Beta $1 \mathrm{R}$

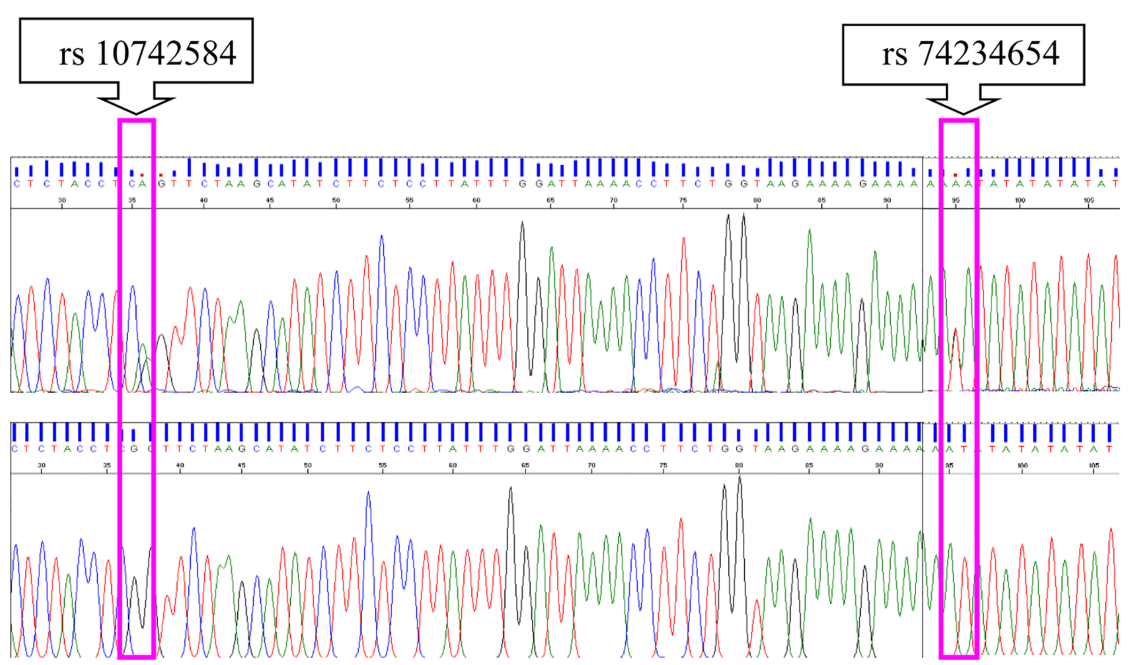

Figure 3 The importance of the fetal DNA enrichment steps. The double peaks (adenine and thymine) were observed in the enriched free-circulating fetal DNA sample, while only a single peak (thymine) was observed in the non-enriched free-circulating fetal DNA sample. This result suggests that enriched fetal DNA extracted from maternal plasma increases the detection sensitivity of paternal SNP by reducing the concentration of free-circulating maternal DNA. SNP, single nucleotide polymorphism.

to high background concentration of fcMDNA, which masks the minute concentration of fcFDNA in the maternal plasma. fcMDNA is generally longer than fetal DNA as it is mainly contributed to by lysis of maternal white blood cells. In addition, Kimura et $a l^{22}$ and Chan $e t a l^{23}$ showed that the fragment length of fcFDNA extracted from maternal plasma was shorter than $313 \mathrm{bp}$. Thus, DNA enrichment is an essential step to reduce the concentration of fcMDNA so that the sensitivity of molecular characterisation of fcFDNA can be increased.

As inheritance involves transmission of the haploid genome, the possibility of a fetus inheriting the paternal mutant allele is $50 \%$. At-risk couples of whom both members are heterozygous for the same mutation are advised to undergo prenatal diagnosis using invasive techniques such as CV sampling or amniocentesis. Using the SNP approach developed in this study, half of these at-risk couples may not require invasive prenatal diagnosis when the SNP with paternally-inherited wild-type allele is present or when the SNP with paternally-inherited mutant allele is absent in the fcDNA extracted from maternal plasma.

\section{CONCLUSIONS}

This preliminary study shows that genotyping with AS-PCR primers allows detection of multiple paternal SNPs with the $\beta$-globin gene mutations. The presence of the paternal SNP in the fcDNA indicates the inheritance of either paternal allele, thus allows prediction and exclusion of $\beta$-thalassaemia major in the fetus regardless of whether the parents are both carrying identical mutations or different mutations. In conclusion, the results in this preliminary study show that fetal DNA enrichment followed by AS-PCR in combination with sequence analysis can be applied to predict the genotype of the fetus.
Contributors JJC performed the experiment and prepared the article. JAMAT, $\mathrm{KHC}$ and EG revised the manuscript. PCT assisted in sample collection. All the authors have read and approved the final version of this manuscript.

Funding This work was supported by the Exploratory Research Grant Scheme (ERGS: ER004-2011A).

Competing interests None declared.

Ethics approval Ethical approval was obtained from the Medical Ethics Committee of University Malaya Medical Centre (MEC Ref No: 896.8) in accordance with the Declaration of Helsinki.

Provenance and peer review Not commissioned; externally peer reviewed.

Data sharing statement No additional data are available.

Open Access This is an Open Access article distributed in accordance with the Creative Commons Attribution Non Commercial (CC BY-NC 4.0) license, which permits others to distribute, remix, adapt, build upon this work noncommercially, and license their derivative works on different terms, provided the original work is properly cited and the use is non-commercial. See: http:// creativecommons.org/licenses/by-nc/4.0/

\section{REFERENCES}

1. Modell B, Darlison M. Global epidemiology of haemoglobin disorders and derived service indicators. Bull World Health Organ 2008;86: 480-7.

2. George E. Beta-thalassemia major in Malaysia, an on-going public health problem. Med J Malaysia 2001;60:397-400.

3. Chu T, Burke B, Bunce K, et al. A microarray-based approach for the identification of epigenetic biomarkers for the noninvasive diagnosis of fetal disease. Prenat Diagn 2009;29:1020-30.

4. Lo YM, Corbetta N, Chamberlain PF, et al. Presence of fetal DNA in maternal plasma and serum. Lancet 1997;350:485-7.

5. Lo YM, Tein MS, Lau TK, et al. Quantitative analysis of fetal DNA in maternal plasma and serum: Implications for noninvasive prenatal diagnosis. Am J Human Genet 1998;62:768-75.

6. Bombard AT, Akolekar R, Farkas DH, et al. Fetal RHD genotype detection from circulating cell-free fetal DNA in maternal plasma in non-sensitized RhD negative women. Prenat Diagn 2011;31:802-8.

7. Zhong $X Y$, Holzgreve W, Hahn S. Detection of foetal Rhesus D and sex using foetal DNA from maternal plasma by multiplex polymerase chain reaction. BJOG 2000;107:766-9.

8. Chiu RW, Lau TK, Cheung PT, et al. Noninvasive prenatal exclusion of congenital adrenal hyperplasia by maternal plasma analysis: a feasible study. Clin Chem 2002;48:778-80. 
9. Chiu RW, Lau TK, Leung TN, et al. Prenatal exclusion of beta thalassaemia major by examination of maternal plasma. Lancet 2002;360:998-1000.

10. Li Y, Di Naro E, Vitucci A, et al. Detection of paternally inherited fetal point mutations for $\beta$-thalassemia using size-fractionated cell-free DNA in maternal plasma. JAMA 2005;293:843-9.

11. Wright $\mathrm{CF}$, Burton $\mathrm{H}$. The use of cell-free fetal nucleic acids in maternal blood for non-invasive prenatal diagnosis. Hum Reprod Update 2009;15:139-51.

12. Ding C, Chiu RW, Lau TK, et al. MS analysis of single-nucleotide differences in circulating nucleic acids: application to noninvasive prenatal diagnosis. Proc Natl Acad Sci USA 2004;101:10762-7.

13. Chua YA, Abdullah WZ, Yusof $Z$, et al. A new nested allele-specific multiplex polymerase chain reaction method for haplotyping of VKORC1 gene to predict warfarin sensitivity. Bio Med Res Int 2014;2014:6.

14. Gayden T, Regueiro M, Martinez L, et al. Human Y-chromosome haplotyping by allele-specific polymerase chain reaction. Electrophoresis 2008;29:2419-23.

15. Pettersson M, Bylund M, Alderborn A. Molecular haplotype determination using allele-specific PCR and pyrosequencing technology. Genomics 2003:82:390-6.

16. Jorgez CJ, Bischoff FZ. Improving enrichment of circulating fetal DNA for genetic testing: size fractionation followed by whole gene amplification. Fetal Diagn Ther 2009;25:314-19.
17. Bustamante-Aragones A, Gallego-Merlo J, Trujillo-Tiebas MJ, et al. New strategy for the prenatal detection/exclusion of paternal cystic fibrosis mutations in maternal plasma. J Cyst Fibros 2008;7:505-10.

18. Chen CP, Chern SR, Wang W. Foetal DNA analysed in plasma from a mother's three consecutive pregnancies to detect paternally inherited aneuploidy. Clin Chem 2001;47:937-9.

19. Bruno DL, Stark Z, Amor DJ, et al. Extending the scope of diagnostic chromosome analysis: detection of single gene defects using high-resolution SNP microarrays. Hum Mutat 2011;32:1500-6.

20. Pergament E, Cuckle H, Zimmermann B, et al. Single-nucleotide polymorphism-based noninvasive prenatal screening in a high-risk and low-risk cohort. Obstet Gynecol 2014;124(2 Pt 1):210-18.

21. Phylipsen M, Yamsri S, Treffers EE, et al. Non-invasive prenatal diagnosis of beta-thalassemia and sickle-cell disease using pyrophosphorolysis-activated polymerization and melting curve analysis. Prenat Diagn 2012;32:578-87.

22. Kimura $M$, Hara $M$, Itakura $A$, et al. Fragment size analysis of free fetal DNA in maternal plasma using Y-STR loci and SRY gene amplification. Nagoya J Med Sci 2011;73:129-35.

23. Chan AKC, Zhang J, Hui ABY, et al. Size distributions of maternal and fetal DNA in maternal plasma. Clin Chem 2004;50:88-92. 